\title{
Feynman e suas conferências sobre o ensino de física no Brasil
}

Feynman and his lectures on physics teaching in Brazil

\author{
Ildeu de Castro Moreira*1
}

${ }^{1}$ Universidade Federal do Rio de Janeiro, Instituto de Física, Cidade Universitária, Rio de Janeiro, RJ, Brasil

Recebido em 05 de Dezembro, 2017. Revisado em 15 de Fevereiro, 2018. Aceito em 20 de Fevereiro, 2018.

Entre 1949 e 1966, o físico norte-americano Richard Feynman veio ao Brasil algumas vezes. Interagiu com físicos brasileiros, realizou pesquisas, deu cursos, fez conferências e participou do carnaval carioca. Por duas vezes, em 1952 e 1963, fez palestras sobre o ensino de física. Suas observações e opiniões sobre este ensino ganharam notoriedade ao serem divulgadas posteriormente em um de seus livros de grande circulação mundial: R. P. Feynman, "Está a brincar, Sr. Feynman!". No livro, ele descreve situações de sua interação com estudantes brasileiros, que ilustram sua crítica ao ensino livresco, baseado na memorização e sem a dimensão investigativa e crítica. O objetivo deste trabalho é analisar as duas conferências de Feynman sobre o ensino de física no Brasil, avaliar a possível influência local de suas observações, críticas e sugestões, e buscar fazer, de maneira retrospectiva, algumas comparações preliminares sobre a situação atual do ensino de física e as considerações por ele feitas há mais de cinco décadas atrás. Reproduziremos, no final, a tradução da segunda conferência de Feynman, "O problema de ensinar física na América Latina" (1963) pelo interesse, ao menos histórico, que ainda guarda.

Palavras-chave: Richard Feynman, ensino de física, história da física no Brasil.

Between 1949 and 1966, the American physicist Richard Feynman came to Brazil a few itimes. He did research and interacted with local physicists, gave courses and lectures and participated in the Rio carnival. Twice, in 1952 and 1963, he lectured on physics teaching. His observations and insights on this teaching gained notoriety as they were later revealed in one of his world-wide books: R. P. Feynman, "You're joking, Mr. Feynman!" In the book he describes situations of his interaction with Brazilian students, which illustrate his criticism of book-based teaching, based on memorization and without the investigative and critical dimension. The objective of this work is to analyze Feynman's two lectures on physics teaching in Brazil, to evaluate the possible local influence of his observations, criticisms and suggestions, and to seek retrospectively some preliminary comparisons on the current situation of teaching physics in Brazil with the considerations he made more than five decades ago. We shall reproduce, in the end, the translation of Feynman's second lecture, "The Problem of Teaching Physics in Latin America" (1963).

Keywords: Richard Feynman, physics teaching, history of physics in Brazil.

\section{Introdução: Feynman no Brasil}

Richard Feynman esteve algumas vezes no Brasil, entre 1949 e 1966. Em um período sabático de dez meses (1951/52), lecionou na graduação em física e engenharia da Universidade do Brasil e deu cursos avançados no Centro Brasileiro de Pesquisas Físicas (CBPF). Em 1949, fez conferência sobre eletrodinâmica quântica (1949) e também sobre o ensino de física (1952 e 1963). O objetivo deste artigo é descrever e analisar estas suas duas conferências sobre o ensino.

Feynman veio pela primeira vez ao Brasil, em 1949, convidado por Jaime Tiomno. Após passar por Recife, permaneceu no Rio de Janeiro por cerca de seis semanas, tendo realizado pesquisas no recém-criado CBPF. Neste

*Endereço de correspondência: ildeucastro@gmail.com período participou do Seminário de Ciências, organizado pela Academia Brasileira de Ciências, onde fez a palestra "A Eletrodinâmica Quântica", na qual discutiu o estado da arte e relatou os avanços, então recentes, realizados por ele e por outros físicos de destaque ${ }^{1}$. Retornou ao Brasil, dois anos depois, em período sabático e na época do Macartismo. Atuou, então, como professor no CBPF e no Departamento de Física da Universidade do Brasil (UB), entre setembro de 1951 e maio de 1952. Em depoimento ao Centro de Pesquisa e Documentação de História Contemporânea do Brasil (CPDOC), Leite Lopes relata esta vinda de Feynman:

"Em 1950, o convidei para que viesse, conseguimos um dinheiro, já não me lembro como. Ele teve o ano sabático de 1951/52, que veio passar no Rio, conosco. Eu era professor na 
Faculdade de Filosofia, Lattes era professor de Física Nuclear, e uma cadeira minha de Teoria Eletromagnética passei ao Feynman para que ele desse. Aprendeu português, falava razoavelmente, deu o curso o ano inteiro na Faculdade de Filosofia e no Centro"."

Neste período, Feynman lecionou cursos avançados de física no CBPF e também realizou pesquisas cientificas, uma delas em parceria com Leite Lopes, que se traduziram em dois artigos em publicações locais ${ }^{3,4}$. Em novembro de 1951, Feynman esteve em Belo Horizonte participando da III Reunião Anual da Sociedade Brasileira para o Progresso da Ciência (SBPC), onde apresentou duas comunicações.

Em 5 de maio de 1952, Feynman realizou sua primeira palestra, no Rio de Janeiro, sobre a situação do ensino de física, escorada em sua experiência como professor para alunos de física e de engenharia na UB. Feynman retornaria ao Brasil em junho/julho de 1963, período no qual participou da I Conferência Interamericana sobre o Ensino de Física, de 24 a 29 de junho, e da II Conferência Internacional sobre a Física na Educação Geral, de 1 a 7 de julho de 1963, promovida pela International Union of Pure and Applied Physics (IUPAP). Na I Conferência Interamericana, realizou uma palestra sobre o ensino de física na América Latina, baseada em sua experiência de anos antes, no Brasil, e em suas interações com colegas brasileiros e de outros países latino-americanos.

Feynman ainda voltaria ao Brasil algumas vezes, as últimas delas para atividades relacionadas à sua participação no carnaval carioca. Em 1966, permaneceu no Rio de Janeiro entre 17 e 23 de fevereiro, juntamente com sua esposa Gweneth, como convidado especial da Prefeitura do Rio de Janeiro para o carnaval da cidade.

\section{A conferência de Feynman sobre o ensino de física no Brasil em 1952}

Feynman fez sua primeira conferência sobre ensino de física no Brasil, em maio de 1952; nos meses anteriores tinha dado cursos para alunos de Física (eletromagnetismo) e Engenharia na UB. Quando encerrava suas atividades do período sabático no Brasil, foi convidado para fazer uma palestra para estudantes, professores e autoridades educacionais sobre as suas impressões e opiniões referentes à experiência que teve com o ensino superior no Brasil. "Minha experiência como professor no Brasil": este foi o título da conferência que se realizou no salão nobre da Faculdade Nacional de Filosofia, dia 5 de maio às $20 \mathrm{~h} 30 \mathrm{~min}$. Ela foi patrocinada pela SBPC (Divisão do Rio de Janeiro), pelo Departamento de Física e pelo Diretório Acadêmico daquela faculdade.

Não conseguimos localizar um texto ou anotações de Feynman sobre esta conferência, além do que ele mencionou em seu livro ${ }^{5}$. Possivelmente ela foi a base para a outra conferência sobre ensino de física, "O problema de ensinar física na América Latina", que realizou no Rio de Janeiro onze anos depois. Mas há um interessante relato da palestra de 1952, e de sua repercussão local, feito pelo biólogo Oswaldo Frota-Pessoa, que também se dedicou, por décadas, à educação e à divulgação científica escrevendo muitas colunas em jornais e publicando livros de ciências. Em um artigo, publicado em sua coluna Ciência em Marcha, no Jornal do Brasil de 25 de maio de 1952, Frota-Pessoa descreveu a palestra de Feynman.

\begin{abstract}
"Assisti uma conferência espantosa. Um físico de fama mundial no setor da eletrodinâmica quântica, Richard P. Feynman, do California Institute of Technology (EUA), nos disse, em português claro, embora estropiado (um ano de Brasil), que, em verdade, não estamos ensinando ciência e nossos alunos não estão aprendendo. (...) E o pior é que ele tem toda a razão. Feynman é um homem raro: diz diretamente o que pensa e tudo o que pensa: e diz com tal entusiasmo e amor que se torna ao mesmo tempo contundente e encantador. "A ciência tem valor" e "não estamos ensinando nada" foram as duas únicas ideias que Feynman disse que ia desenvolver já que a terceira - "como ensinar bem" - transcendia da competência dele, que é pesquisador e não pedagogo.
\end{abstract}

"Mas a verdade é que nos disse o mais importante sobre como ensinar. Ciência é a descrição dos fenômenos da Natureza, postulou ele, referindo-se as ciências físicas naturais (e não à matemática). Ensinar ciência é, portanto, pôr os alunos em contato com os fenômenos naturais. O ensino usual, adstrito a definições e formulas mortas memorizadas ou mesmo entendidas, não chega a ser ensino de ciência. Só quando o estudante está pesquisando fatos reais, que efetivamente se estão desenrolando perante ele (e não imaginariamente no quadro negro), só quando investiga, aguçado pela curiosidade e pelo encantamento ante o mistério, está ele aprendendo ciência. (...) O maior valor da ciência, diz Feynman, é alimentar a curiosidade e nos dar o inigualável prazer de desvendar o desconhecido. Devemos ensiná-la para ampliar o círculo dos que podem participar da deliciosa aventura de conhecer." 6

Frota-Pessoa relata ainda as críticas feitas por Feynman aos livros didáticos que são, "em geral, como que dicionários, sem ordem alfabética: mas dicionários de definições, de palavras mortas, de conceitos que, por não terem emergido diretamente dos fatos, pertencem a um mundo artificial e inútil criado pelo complot pedagógico contra a inteligência do jovem. Nossos autores didáticos 
são na maioria puros compiladores: e quem não pesquisa, não lida com os fatos, não consegue fazer um livro vivo, que aguce o interesse e a iniciativa do leitor."

Uma avaliação geral sobre a conferência e os debates que se seguiram foi feita por Frota-Pessoa:

"O prof. Costa Ribeiro, (...), comentou com muita agudeza, durante os debates que se seguiram, que Feynman tem o bom senso sadio das crianças (e, acrescentamos, redobrando o elogio, a mesma ausência de respeito humano). Comparou-o ao menino que, naquele conto bem conhecido, foi a única pessoa a dizer que o rei estava nu. Envolvido em nosso narcisismo, mantemos a convenção de que temos um sistema universitário, senão perfeito, pelo menos muito satisfatório. Feynman nos diz que é péssimo, e o demonstra com incrível simplicidade, baseado em fatos que estamos fartos de conhecer e nos quais fechamos os olhos - olhos que ele nos obriga a abrir, e que se abrem, então, estarrecidos e atônitos. Se queremos realmente fazer progredir a ciência no Brasil, urge revolucionar nossos métodos didáticos, em todos os níveis: primário, secundário e superior. A falta de formalidades, pedantismo e academicismo que caracterizou a reunião foi uma das condições de sucesso. Os prolongados debates, em que participaram, com Feynman, alunos e professores da Faculdade, em seguida à conferência, se caracterizaram por ideias objetivas e sugestões felizes para melhoramento dos nossos métodos de ensino. Esperemos que este magnifico impulso inicial nos leve longe." ${ }^{6}$

Estas apreciações de Frota-Pessoa permitem aquilatar que não foi pequeno o impacto local que a conferência de Feynman produziu, além de destacar o envolvimento que ela gerou entre professores e estudantes. Uma confirmação disto está expressa no editorial da revista Ciência e Cultura da SBPC, em seu primeiro número de 1952. Escrito possivelmente por José Reis, que era seu principal editor, o editorial se intitulava "Ensino de Ciências na Universidade" e relata, em dois longos parágrafos, o conteúdo central da exposição feita por Feynman:

"Uma crítica mais franca e portanto mais acerba do ensino que é ministrado nas nossas universidades foi feita pelo Prof. Richard P. Feynman, físico especialista em eletrodinâmica quântica, e que há um ano colabora com o Centro Brasileiro de Pesquisas Físicas, no Rio de Janeiro. O Prof. Feynman, com uma franqueza que só os verdadeiros pesquisadores da verdade científica costumam ter, realizou uma conferência sobre o ensino da ciência, sob os auspícios do Departamento de Física e
Diretório Acadêmico da Faculdade Nacional de Filosofia, patrocinada ainda pela Divisão Regional da SBPC. De início, o prof. Feynman declarou que ia basear a sua conferência em dois pontos fundamentais: $1^{\circ}$ ) A ciência tem valor e $2^{\circ}$ ) não estamos ensinando ciência. Desenvolvendo esses temas de importância transcendental, o prof. Feynman afirma o que todos sabemos, que a ciência é a descrição dos fenômenos das natureza, mas continuou afirmando o que nem todos nós sabemos, que ensinar ciência é pôr os alunos em contato com os fenômenos naturais e que o ensino usual, de memorizar fórmulas e definições, não é ensinar ciência; só quando o estudante está pesquisando fatos reais que efetivamente se desenrolam perante os seus olhos (e não no quadro negro), só quando investiga, aguçado pela curiosidade e pelo encantamento ante o desconhecido, é que está aprendendo ciência. O maior valor da ciência, continua o prof. Feynman, é alimentar a curiosidade e nos dar o ineguável prazer de desvendar o desconhecido.

Parece claro, portanto, que o essencial num ensino universitário é o desenvolvimento desse espírito de pesquisa, o que só pode ser transmitido aos alunos por aqueles que realmente o têm. Essa verdade, que é óbvia para o prof. Feynman, é ainda obscurecida por espesso véu que a esconde dos olhos da maioria dos responsáveis pelas nossas universidades. Essa situação foi comentada de maneira sutil pelo prof. J. Costa Ribeiro durante a discussão que se seguiu à palestra do prof. Feynman. O prof. Costa Ribeiro, de maneira feliz, evocou a conhecida fábula das roupas do rei, que eram admiradas por todos até que um garoto da rua, com uma franqueza só comparável à do prof. Feynman, levantou a questão: mas o rei está nu!"7

O contexto local, que possibilitou e estimulou esta conferência de Feynman, foi descrito em depoimento de Leite Lopes ao CPDOC. Neste depoimento, Leite Lopes mencionou também uma repercussão relevante das considerações de Feynman sobre o ensino de física no Brasil: elas teriam estimulado a tradução de um livro norte-americano para o ensino de física, feita por ele e por Jaime Tiomno.

"Uma pessoa como Feynman passou um ano sabático conosco, isso não é para todo mundo e não é todo sujeito genial como ele que passa numa instituição que não mereça nada. Criticou, fez conferência criticando. O que o Feynman fez foram conferências, provocadas por 
nós. Pegava os livros de Física de curso secundário escritos por brasileiros, que eram muito formais, cheios de Matemática, copiando livros franceses. Ele fez uma conferência pegando livros e arrasando, criticava muita coisa que era uma tradição antiga. Mas nós devíamos ter defeitos também, éramos peixes na água brasileira, mas concordávamos com isso e achávamos que uma pessoa, como Feynman, dizendo, teria maior repercussão do que se nós disséssemos porque seríamos os inimigos daqueles que escreveram [os livros].

Depois disso, o Tiomno e eu traduzimos e adaptamos para o Brasil, em português, um livro de Física, americano, que foi editado, deve existir ainda, no Blackwood ${ }^{8}$ e não sei mais quem, já não me lembro mais. Era um livro de Física intuitivo, mostrando como se fazem as coisas. Contra o formalismo vazio exatamente daqueles que teriam tendências a cultivar a chamada Mecânica Tradicional, ter fórmula para o objetivo de obter fórmulas." ${ }^{2}$

A decisão de Leite e Tiomno de traduzir este livro está escorada na avaliação sobre a situação do ensino de física no nível médio que fizeram poucos meses após a conferência de Feynman, e que publicada na revista Ciência e Cultura de março de 1953 com o título: "O Ensino da Física nos Cursos Secundários". Ali eles propuseram, entre outras sugestões para a melhoria do ensino, que deveria haver um livro-padrão para o curso secundário e qual livro deveria ser este:

"É nossa opinião que o livro-padrão adotado seja o de Blackwood, Herron e Kelly, HighSchool Physics, convenientemente traduzido e adaptado às condições brasileiras. Ou um livro especialmente escrito, dentro do espírito acima mencionado. É conveniente que o livro seja também utilizado pelo estudante."10

\section{O problema de ensinar física na América Latina - 1963}

"O problema de ensinar física na América Latina" foi a conferência realizada por Feynman no Rio de Janeiro, em 1963, no Palácio da Cultura. Ela ocorreu durante a I Conferência Interamericana de Ensino de Física, no final de junho daquele ano. Seu conteúdo foi publicado na revista Engineering and Science do mesmo ano ${ }^{11}$ e sua tradução está colocada no Anexo. Observe-se que ela ocorre no período em que Feynman estava lecionando cursos introdutórios de física no Caltech, nos anos acadêmicos 1961-62 e 1962-63, para estudantes de graduação e que se transformaram em suas famosas Lectures on Physics, em três volumes.
Neste artigo, Feynman iniciou por pontuar que o problema do ensino de física não é só da América Latina e que ele desafia soluções satisfatórias em todo o mundo. Por isto, defende a postura de que devem ser tentadas soluções modestas e que possam ser avaliadas e corrigidas paulatinamente. Em seguida, elencou as principais razões pelas quais é importante ensinar física: i) a física é uma ciência básica, que é útil para as outras ciências e para as aplicações tecnológicas; ii) a física ensina a manipular as coisas, e as suas diversas técnicas, como fazer cálculos e medir, são usadas em diversas áreas. Para Feynman seria vitalmente importante para a América Latina aprimorar a habilidade técnica das pessoas locais; a importação de pessoal qualificado não lhe parecia uma solução adequada para o desenvolvimento; iii) a ciência é um importante elemento da cultura. A física é significativa 'pela ciência em si', pelo desenvolvimento do conhecimento em geral e pela apreciação das maravilhas e belezas da natureza que proporciona; iv) a física ensina como as coisas podem ser descobertas, e promove o valor de se questionar e de se ter liberdade de pensamento; v) a física ajuda a desenvolver o espírito inventivo, o aprendizado do processo de tentativa e erro, e exibe a importância do pensamento livre, que tem imenso valor para a humanidade em todas as áreas.

Em uma análise, que pretendeu mais geral para a América Latina, mas baseada em sua experiência como professor no Brasil, Feynman expôs, em seguida, as principais características e dificuldades que percebia no ensino de física: i) primeiramente, e o fator mais importante, é que o ensino /aprendizado é quase exclusivamente baseado em memorização. Aqui, Feynman relata várias experiências neste sentido que teve com estudantes da UB e que depois reproduziria em seu livro ${ }^{5}$; ii) os estudantes atuam sempre sozinhos e não interagem ou discutem com seus colegas; iii) a falta de liberdade no ambiente universitário; isto impede os estudantes de mudarem de área ou de laboratório; iv) pouca atenção é dada ao conjunto maior de estudantes que não pretendem ser cientistas; v) outro ponto característico da América Latina é o pequeno número de pessoas envolvidas em atividades cientificas, o que torna as organizações e instituições irregulares e instáveis; vi) os melhores alunos tendem a sair de seus países e se dirigirem para o exterior.

Os desafios centrais que apontou, na forma de questões, foram: i) como nos livrar, já nos níveis da educação secundária, da carga pesada da memorização hoje existente? ii) como aproximar os engenheiros e outros cientistas aplicados do mundo real? Aqui ele destacou a importância da ciência experimental para os engenheiros; iii) como estimular os outros pesquisadores e mantê-los nas instituições? Sugeriu aqui o oferecimento de recursos, de condições materiais adequadas e de viagens periódicas ao exterior; iv) como fazer com que os pesquisadores retornem às universidades às quais pertencem?; v) por último, Feynman destacou que todas estas ações devem ser feitas de forma permanente, consistente, continuada e 
de forma modesta. Ressalte-se, ainda, a importância dada por Feynman ao papel e às atitudes dos bons professores.

Como se vê, esta conferência de Feynman foi particularmente interessante por abordar de forma integrada, além das dificuldades e desafios do ensino de física na América Latina, algumas questões centrais relativas ao desenvolvimento científico e tecnológico da região e expor suas opiniões e sugestões sobre isto. É interessante ressaltar, ainda, que, em um dos debates ocorridos durante a II Conferência Internacional sobre a Física na Educação Geral, o professor do MIT Sanborg C. Brown defendeu que o ensino de física deveria se iniciar com crianças de seis anos em diante. Feynman discordou do palestrante e da quase unanimidade dos presentes sobre isto - segundo a matéria do Jornal do Brasil, de 7 julho de 1963 - e considerou que o ensino de física não deve, em nenhuma hipótese, ser ministrado na infância ${ }^{12}$.

As experiências e observações de Feynman, como professor no Brasil, e analisadas nas duas conferências mencionadas, foram também relatadas por ele, com detalhes pitorescos e agora em um estilo irônico e mesmo debochado, no livro O senhor está brincando, Sr. Feynman!. Reproduzimos, a seguir, alguns dos principais trechos deste relato que possibilitam uma comparação com as considerações feitas em sua conferência de 1952 e em seu artigo de 1963, neste caso apresentadas de forma mais acadêmica e organizada. Em um dos trechos, descreve e critica o ensino baseado em memorização e decoreba:

"Em relação à educação no Brasil, tive uma experiência muito interessante. Eu estava dando aulas para um grupo de estudantes que se tornariam professores, uma vez que àquela época não havia muitas oportunidades no Brasil para pessoal qualificado em ciências. Esses estudantes já tinham feito muitos cursos, e esse deveria ser o curso mais avançado em eletricidade e magnetismo - equações de Maxwell, e assim por diante. Descobri um fenômeno muito estranho: eu podia fazer uma pergunta e os alunos respondiam imediatamente. Mas quando eu fizesse a pergunta de novo - o mesmo assunto e a mesma pergunta, até onde eu conseguia -, eles simplesmente não conseguiam responder! Por exemplo, uma vez eu estava falando sobre luz polarizada e dei a eles alguns filmes polaroide. (...). Depois de muita investigação, finalmente descobri que os estudantes tinham decorado tudo, mas não sabiam o que queria dizer. Quando eles ouviram 'luz que é refletida de um meio com um índice', eles não sabiam que isso significava um material como a água. Eles não sabiam que a 'direção da luz'é a direção na qual você vê alguma coisa quando está olhando, e assim por diante. Tudo estava totalmente decorado, mas nada havia sido traduzido em palavras que fizessem sentido. Assim, se eu perguntasse: 'O que é o Ângulo de Brewster?', eu estava entrando no computador com a senha correta. Mas se eu digo: 'Observe a água', nada acontece - eles não têm nada sob o comando 'Observe a água'."5

Uma de suas experiências com alunos de engenharia, aos quais interroga sobre seus conhecimentos de eletromagnetismo, é assim descrita:

"Então fui a um exame de admissão para a faculdade de engenharia. Era uma prova oral e eu tinha permissão para ouvi-la. Um dos estudantes foi absolutamente fantástico: ele respondeu tudo certinho! Os examinadores perguntaram a ele o que era diamagnetismo e ele respondeu perfeitamente. (...) Depois da prova, fui até esse brilhante jovem e expliquei que eu era dos Estados Unidos e que eu queria fazer algumas perguntas a ele que não afetariam, de forma alguma, os resultados da prova. A primeira pergunta que fiz foi: "Você pode me dar algum exemplo de uma substância diamagnética?" - Não." 5 .

Uma crítica diversa se refere à dificuldade dos alunos de engenharia, para os quais lecionava, de fazerem perguntas e exibirem seu desconhecimento de determinado conteúdo:

"Então continuei a aula e, independente de quão complexo ou obviamente avançado o trabalho estivesse se tornando, eles nunca punham a mão na massa. É claro que eu já havia notado o que acontecia: eles não conseguiam fazer! Uma outra coisa que nunca consegui que eles fizessem foi perguntas. Por fim, um estudante explicou-me: "Se eu fizer uma pergunta para o senhor durante a palestra, depois todo mundo vai ficar me dizendo: "Por que você está fazendo a gente perder tempo na aula? Nós estamos tentando aprender alguma coisa, e você o está interrompendo, fazendo perguntas. Era como um processo de tirar vantagens, no qual ninguém sabe o que está acontecendo e colocam os outros para baixo como se eles realmente soubessem. Eles todos fingem que sabem, e se um estudante faz uma pergunta, admitindo por um momento que as coisas estão confusas, os outros adotam uma atitude de superioridade, agindo como se nada fosse confuso, dizendo àquele estudante que ele está desperdiçando o tempo dos outros." 5

Ele destacou, ainda, a importância para o aprendizado de se trabalhar em grupo:

"Expliquei a utilidade de se trabalhar em grupo, para discutir as dúvidas, analisá-las, 
mas eles também não faziam isso porque estariam deixando cair a máscara se tivessem de perguntar alguma coisa a outra pessoa. Era uma pena! Eles, pessoas inteligentes, faziam todo o trabalho, mas adotaram essa estranha forma de pensar, essa forma esquisita de autopropagar a "educação", que é inútil, definitivamente inútil!"5

\section{E como estamos no ensino de física hoje?}

Uma comparação interessante a ser feita é buscar relacionar os problemas atuais do ensino de física no Brasil com aqueles percebidos e relatados por Feynman, dentro de sua ótica de professor norte-americano e físico teórico, com experiência limitada sobre a situação de nosso ensino, e produzida seis décadas atrás. É importante recordar que ele comentou principalmente o problema do ensino de física na universidade, para físicos e engenheiros. Quando se referiu ao ensino médio, sobre o qual tinha pouca experiência pessoal no Brasil, criticou particularmente o aspecto de um ensino baseado na memorização e ainda o fato de que o ensino não levava em conta os estudantes que não pretendiam continuar em carreiras acadêmicas. Mas algumas de suas críticas ao ensino universitário aplicavam-se também ao nível secundário, como o fato dos estudantes interagirem ou discutirem pouco com seus colegas, a ausência de atividades experimentais e a pouca flexibilidade curricular. Outros pontos apontados por ele para o ensino superior, como a má qualidade dos livros didáticos ou o salário baixo dos professores, poderiam ser também estendidos ao ensino secundário.

Para fazer uma comparação, ainda que preliminar e limitada a apenas um ou dois aspectos dos comentários críticos de Feynman, com a situação atual do ensino de física em anos mais recentes, escolhemos fazê-lo a partir de um texto geral do professor Marco Antônio Moreira, conhecido educador em física, que publicou o artigo Ensino de Física no Brasil: Retrospectiva e Perspectivas, cerca de quatro décadas após a segunda conferência de Feynman $^{13}$. Quando se refere ao ensino de graduação em física, Moreira faz uma crítica dura e que retoma alguns dos principais comentários de Feynman, entre os quais a dependência estrita ao livro-texto. Algumas dessas observações possivelmente poderiam ser atenuadas com o passar dos últimos anos e em instituições localizadas que se preocuparam mais com a melhoria do ensino universitário; guardam ainda, no entanto, e infelizmente, grande parte de razão.

"Passemos ao ensino de Graduação em Física. A parece que nunca saímos do paradigma do livro. Em nosso ensino de graduação, tanto nas disciplinas de Física Geral como nas avançadas, e o livro de texto que determina o nível do curso, a ementa, o programa, a sequência das aulas, enfim, o plano de ensino da disciplina. O laboratório parece ser uma obrigação incômoda para muitos professores; o ideal aparenta ser explicar, ou simplesmente repetir, o que está no livro e dar uma lista de problemas aos alunos. Infelizmente, nosso ensino de graduação em Física é muito ruim. A evasão em nossos cursos de Física é enorme. Possivelmente, os estudantes que sobrevivem e acabam saindo bacharéis ou licenciados em Física nem precisassem ter tido o ensino que tiveram. Trata-se muito mais de seleção natural do que de aprender em função do ensino." 13

Moreira descreve o surgimento de livros textos mais elaborados nos EUA, cujas traduções são aqui utilizadas, como o de Halliday-Resnick. Poderia ter mencionado também a extraordinária Lectures on Physics, do próprio Feynman, cuja publicação ocorre entre 1963 e 1965, no período de sua segunda conferência no Brasil, ou a série Berkeley Physics Course, publicada na década seguinte, ambas de excelente qualidade, mas que não conseguiram atingir um grande êxito no ensino básico do ponto de vista de seu uso mais abrangente. No caso brasileiro, tivemos na década de 1970, a meritória e bem escrita série de livros para o ciclo básico de Moysés Nussenzveig, ainda em utilização em alguns cursos. Mas, para Moreira, grandes problemas ainda permanecem com esse modelo de ensino, que está baseado quase que exclusivamente em um livro-texto.

Esta família [de livros] é grande e continua aumentando, mas o ensino da Física introdutória segue problemático e, provavelmente, persistirá assim, na medida que nos mantivermos exclusivamente no paradigma do livro de texto, como se faz há, pelo menos, 150 anos. ${ }^{13}$

Há que se reconhecer que alguns dos pontos críticos apontados por Feynman foram minorados ao longo das últimas décadas no Ensino Médio, pelo menos no que se refere às orientações e diretrizes gerais sobre o ensino de física. Uma análise das Diretrizes Curriculares Nacionais da Educação Básica ${ }^{14}$ mostra que surgiram novas abordagens para o ensino de Física no Ensino Médio, muitas delas atendendo a críticas, como as de Feynman, buscando maior flexibilidade curricular e estimulando o desenvolvimento de práticas investigativas e colaborativas na escola, em contraposição a um processo individualizado e que favorece a mera memorização. Certamente, como apontado por Moreira ${ }^{13}$, tivemos avanços em novas metodologias, um crescimento significativo nas pesquisas em ensino de física, e muitas e boas iniciativas de melhorias espalhadas por diversas escolas e universidades brasileiras nestas últimas décadas. Mas, no geral, o lema "Na prática a teoria é outra" ainda se aplica em 
grande parte ao ensino de física das escolas brasileiras, que permanece com inúmeras das deficiências apontadas. Note-se que outros aspectos mencionados por Feynman tiveram sua intensidade ampliada, como a situação crítica do salário dos professores do ensino médio ou as repercussões de um ensino que se massificou bastante desde então.

\section{Material Suplementar}

O seguinte material suplementar está disponível online: Anexo - O problema do ensino de física na América Latina.

\section{Referências}

[1] Ildeu de Castro Moreira, Feynman's Activities in Brazil: On Quantum Electrodynamics and Physics Teaching (2018). (unpublished)

[2] J.L. Lopes, Depoimento - José Leite Lopes (Fundação Getúlio Vargas, Rio de Janeiro, 2010), p. 46.

[3] J.L. Lopes, R.P. Feynman, On the pseudoscalar meson theory of the deuteron. Physics Note No. 2. Centro Brasileiro de Pesquisas Físicas, Rio de Janeiro, 1952.

[4] R.P. Feynman, An. Acad. Bras. Ciênc. 26, 51 (1954).

[5] R.P. Feynman, 'Está a brincar, Sr. Feynman!': Retrato de um Físico Enquanto Homem (Gradiva, Lisboa, 1998).

[6] I.C. Moreira and M.C. Paiva, Física na Escola 14, 62 (2016).

[7] J. Reis, Cien. Cult. 4, 1 (1952).

[8] O.H. Blackwood, W.B. Herron and W.C Kelly, Física na Escola Secundária (Rio de Janeiro, MEC, 1962).

[9] J.L. Lopes and J. Tiomno, Cien. Cult. 5, 45 (1953).

[10] R.P. Feynman, Engineering and Science, 27, 21 (1963).

[11] Jornal do Brasil, 7 julho, p. 32 (1963).

[12] M.A. Moreira, Rev. Bras. Ens. Fis. 22, 94 (2000).

[13] Ministério da Educação, Diretrizes Curriculares Nacionais da Educação Básica (Ministério da Educação, Brasília, 2003). 